\title{
EL MERCADO INMOBILIARIO EN EL ÁREA METROPOLITANA DE COCHABAMBA-BOLIVIA: CARACTERÍSTICAS E INFLUENCIAS EN LA CONFIGURACIÓN URBANA
}

\section{Juan E. Cabrera y Limbert Cabrera}

\section{RESUMEN}

El artículo expone resultados parciales de un trabajo de monitoreo del mercado inmobiliario del Área Metropolitana de Cochabamba desarrollado entre el año 2013 y 2017 coordinado por la Dirección del Centro de Investigaciones en Arquitectura y Urbanismo. A través de la sistematización de un conjunto amplio de datos alfanuméricos y geográficos, se expone la situación del mercado inmobiliario metropolitano de Cochabamba desde la dimensión de la oferta especializada. En ese marco, el artículo da luces sobre un posible estancamiento y/o desaceleración de la dinámica inmobiliaria regional, lo que sugiere la conclusión del proceso expansivo del sector de la construcción en la última década. En su dimensión geográfica el artículo presenta un análisis que expone algunas particularidades del comportamiento espacial de la oferta de inmuebles en el área de estudio, seguido de una evaluación de características e influencias en la configuración urbana y la segregación socio espacial. Se parte de la hipótesis de que la dinámica del mercado inmobiliario influye más que la planificación en la configuración urbana de la región.

Palabras clave: Mercado inmobiliario, configuración urbana, área metropolitana, Cochabamba.

DOI: 10.23881/idupbo.017.1-6i 